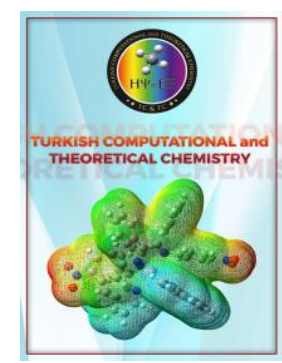

Received: 19.12.2020
Turkish Computational and Theoretical Chemistry

Turkish Comp Theo Chem (TC\&TC)

Volume(Issue): 5(1) - Year: 2021 - Pages: 27-38

e-ISSN: 2602-3237

https://doi.org/10.33435/tcandtc. 843329

Accepted: 22.02 .2021

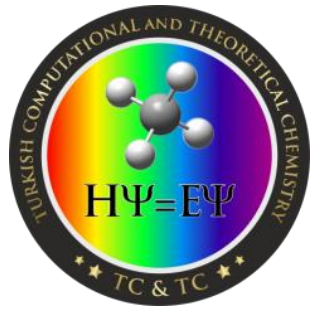

Research Article

\title{
2-Acetyl-5-chloro-thiophene thiosemicarbazone and its nickel(II) and zinc(II) complexes: Hirshfeld surface analysis and Density Functional Theory calculations for molecular geometry, vibrational spectra and HOMO-LUMO studies
}

\author{
Betül ŞEN YÜKSEL ${ }^{l, a}$
}

a Dokuz Eylül University, Department of Physics, 35390, Buca, Izmir, Turkey

\begin{abstract}
In this work, the theoretical studies on the molecular structure are presented for 2-Acetyl-5chloro-thiophene thiosemicarbazone and its $\mathrm{Ni}$ (II) and $\mathrm{Zn}$ (II) complexes. The optimized molecular geometry and fundamental vibrational frequency values have been investigated with the help of DFT/B3LYP method using $6-31 \mathrm{G}(\mathrm{d}, \mathrm{p})$ basis set and they are found to be in agreement with the experimental values. Additionally, frontier molecular orbital energies (HOMO, LUMO) and their energy gaps $(\Delta \mathrm{E})$ are calculated by the same method. The HOMO and LUMO analysis are used to determine some molecular properties such as chemical potential, hardness, softness and electronegativity. Furthermore, Hirshfeld surface analyses and fingerprint plots have been used for visualizing and exploring intermolecular interactions in the crystal structure and for determining the percentage contribution of these interactions on the surface. The Hirshfeld surface analysis and the 2D fingerprint plots indicate that the crystal packing of the compounds is dominated by $\mathrm{Cl} \cdots \mathrm{H} / \mathrm{H} \cdots \mathrm{Cl}, \mathrm{S} \cdots \mathrm{H} / \mathrm{H} \cdots \mathrm{S}, \mathrm{N} \cdots \mathrm{H} / \mathrm{H} \cdots \mathrm{N}$ and $\mathrm{H} \cdots \mathrm{H}$ contacts.
\end{abstract}

Keywords: Thiosemicarbazones, DFT calculations, Hirshfeld surface analysis.

\section{Introduction}

Thiosemicarbazones are versatile ligands, including appropriate donor atoms for coordination to metals $[1,2]$. They have tautomerism such as thione or thiol tautomer, and the ability to coordinate to metal ions either in neutral or anionic form, acting usually as monodentate or bidentate ligands depending on whether the bonding takes place via azomethine nitrogen and thio-carbonyl sulfur atoms $[3,4]$. Thiosemicarbazones, as well as their transition metal complexes, possess a wide variety of pharmacological activity inclusive of antifungal [5,6], antitumor [7,8], antibacterial $[9,10]$, anti-malarial [11,12], antiviral [13] and anticancer $[14,15]$. Particularly, transition metals such as $\mathrm{Co}(\mathrm{II}), \mathrm{Ni}(\mathrm{II}), \mathrm{Cu}(\mathrm{II}), \mathrm{Zn}$ (II) and $\mathrm{Pd}(\mathrm{II})$ coordinated to thiosemicarbazone ligands attract a great deal of interest due to their chemical behavior and biological activity [16]. In addition, metal complexes have been extensively used for device applications in telecommunications, optical computing, optical storage and optical information processing [17].

As seen from the above discussions, these metal complexes are important not only in academic grounds but also they can be treated as potential candidates in technological and medical applications. Therefore, in recent years, we have been working on the structural and biological properties of thiosemicarbazones and their metal complexes. The aim of this study is to give a complete description of the molecular geometry, molecular vibrations and HOMO-LUMO energies of ligand and its two complexes. We also report herein investigation of intermolecular contacts by Hirshfeld surface analysis. Furthermore, the results of calculations obtained by density functional theory (DFT) B3LYP with 6-31G(d,p) level are compared with the experimentally determined

\footnotetext{
${ }^{1}$ Corresponding Authors

e-mail: betul.sen@deu.edu.tr
} 
molecular structure and also with the spectroscopic results.

\section{Method}

\subsection{Synthesis of ligand and its complexes}

The 2-Acetyl-5-chloro-thiophene thiosemicarbazone was synthesized according to the method described in the literature [18] while complexes were prepared from 2-Acetyl-5-chlorothiophene thiosemicarbazone by the literature procedure [15].

\subsection{Crystal structures of ligand and its complexes}

The crystal structures of the ligand and complexes were determined by the X-ray diffraction method in previous studies $[15,18]$.

\subsection{Computational details}

Density functional theory calculations using the Becke's three parameter hybrid functional were performed using Lee-Yang-Parr correlation functional implemented with 6-31G(d,p) [19-21]. The geometrical parameters, frontier molecular orbital energies and vibrational frequency (FT-IR) calculations were carried out by using the Gaussian 09W program package [22]. The structure of the optimized geometry and pictures of HOMOLUMO energies were constructed by GaussView 5.0 [23] program. The structures obtained from the optimized geometry of all compounds were stable structures due to the absence of imaginary frequencies in the calculated IR spectrum.

\subsection{Hirshfeld surfaces computational method}

The determination of Hirshfeld surface (HS) and analysis of the corresponding fingerprint plot (FP) provide us an efficient and reasonably effective method for the aims of the visualization and comparison of various intermolecular interactions present within a crystal structure. The fingerprint plot represents the two-dimensional (di, de) contacts, where di indicates the distance from a point on the surface to the nearest nucleus inside the surface and de indicates the distance of the nearest nucleus outside the surface on HS. The normalized contact distance dnorm, is based on both di and de, each of which is normalized by the van der Waals radii of their corresponding atoms involved in the close contact to the surface. The value of dnorm is negative when intermolecular contacts are shorter than the sum of the van der Waals radii of the two atoms, which is visualized as red spots in the Hirshfeld surface. The white color denotes the contacts with distances close to the sum of the van der Waals radii corresponding to dnorm value of zero while contacts longer than the sum of van der Waals radii resulting in positive dnorm value are highlighted in blue color on the surface. The threedimensional HSs [24] mapped to dnorm and their associated two-dimensional FPs analysis, as well as shape-index and curvedness presented in this study were generated for all compounds based upon the crystallographic information file (CIF) using CrystalExplorer 3.1 [25].

\section{Results and discussion}

\subsection{Molecular geometry}

For the theoretical investigation of structures, the starting geometry was obtained from the X-ray structure determination, and the molecular geometry was optimized using DFT in the ground state. The optimized geometric structures of all compounds are shown in Figure 1. Some optimized parameters such as bond lengths and bond angles are given in Table 1 and compared with the experimental data.

The root mean square error (RMSE) reported by Palafox [26] is used for a comparison of theoretical and experimental values for geometric parameters. The RMSE is separately calculated for geometric parameters, namely the bond length and the bond angle for each complex.

The RMSE values are obtained as $0.023 \AA$ (ligand), $0.027 \AA$ (Zn-complex) and $0.024 \AA$ (Ni-complex) for bond length whereas they are found as $1.30 \AA$ (ligand), $2.32 \AA$ (Zn-complex) and $1.37 \AA(\mathrm{Ni}-$ complex) for bond angle. Zn-complex has the largest deviation in bond angles between experimental and calculated values due to the mismatch of bond angles around metal atom. Coordination environment bond angles which have the greatest difference between experimental and theoretical values are observed as 117.90 and 113.21o for S1-Zn1-S1i and $\mathrm{Cl} 2-\mathrm{Zn} 1-\mathrm{Cl} 2 \mathrm{i}$ whereas they are calculated as112.20 and 120.60. Note that the reason for general deviation in results is that the intra- and intermolecular forces present 
in the solid state are taken into account in the X-ray study whereas these forces are not considered in the calculations.

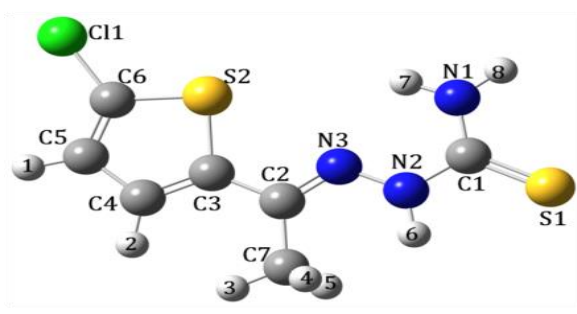

(a)

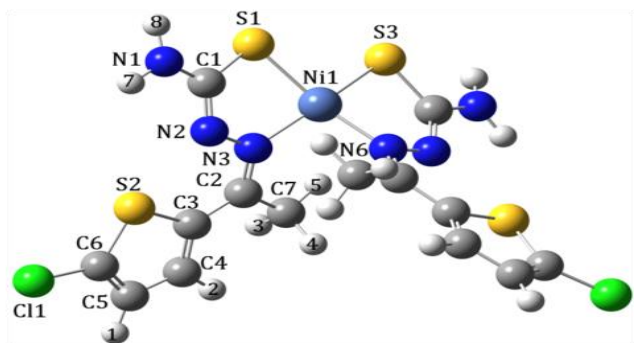

(c)

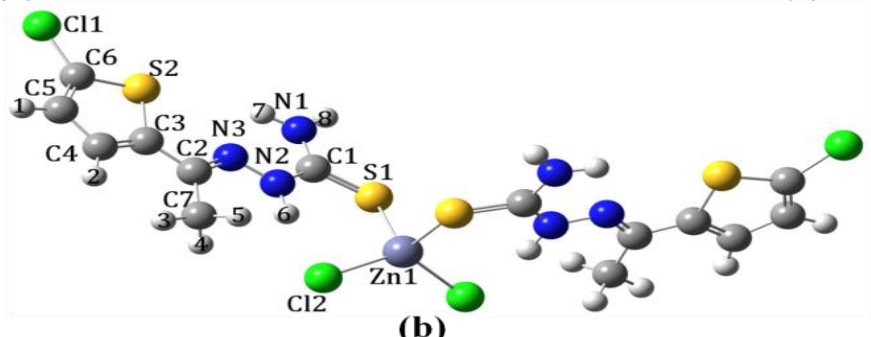

Figure 1. The optimized structures of (a) Ligand, (b) Zn-complex and (c) Ni-complex

\subsection{HOMO-LUMO Analysis}

Frontier molecular orbitals (FMOs) analysis plays an important role in determining molecular electrical transport properties and molecular stability. LUMO (the lowest unoccupied molecular orbital) acts as an electron acceptor representing the ability to obtain an electron while HOMO (highest occupied molecular orbital) is regarded as an electron donor representing the ability to donate an electron. According to Figures 2a-b, the LUMO of ligand and $\mathrm{Zn}$-complex is mainly located on the 5chloro thiophene rings. Besides, the HOMO is found to be localized around the whole molecule except the methyl group for ligand while it is distributed over the whole molecule except the methyl group, $\mathrm{Zn}$ and $\mathrm{Cl}$ atoms for $\mathrm{Zn}$-complex. The orbital diagrams of Ni-complex in Figure $2 \mathrm{c}$ indicate that HOMO is located over the whole of the molecule except the methyl groups and 5-chloro thiophene rings whereas LUMO is spread over the entire molecule except $\mathrm{CH} 3$ group, $\mathrm{Ni}$ atom and $\mathrm{S}$ atoms bonded to $\mathrm{Ni}$ atom. The distributions and energy levels of the HOMO and LUMO orbitals are calculated at the B3LYP level for compounds. Some quantities related to energies such as the chemical hardness $(\eta=($ ELUMO-EHOMO $) / 2)$, chemical softness $(S=1 / 2 \eta)$ and the electronegativity ( $\square=-($ ELUMO+EHOMO)/2) are also computed from LUMO and HOMO energy values. The HOMO-LUMO energy gap $(\Delta \mathrm{E})$ is an important stability parameter indicating the chemical stability of the molecule. The molecular orbital energy gap for the ligand is $3.691 \mathrm{eV}$ which can be compared with those obtained for $\mathrm{Zn}$ complex (3.966 eV) and Ni-complex (3.363 eV). According to Table 2, we can conclude that the large energy gap, highest hardness and lowest softness indicate that $\mathrm{Zn}$-complex is more stable and less reactive than ligand and $\mathrm{Ni}$-complex.

\subsection{Vibrational spectra}

Calculated harmonic vibrational frequencies may be usually found to be greater than those obtained for the corresponding experimental values due to the lack of properly inclusion of the electron correlation effects and basis sets deficiencies in the calculations [27]. In this regard, by using a proper scale factor, it may be possible to obtain theoretical results that are in agreement with the experimental values. In the present study, the calculated harmonic frequencies are scaled down using a single scaling factor 0.9608 for B3LYP/6-31G (d,p) [28]. Selected calculated vibrational frequencies of the compounds and their assignments are shown in Table 3.

RMSE values are found to be 14.74, 20.09 and $19.40 \mathrm{~cm}-1$, respectively for ligand, $\mathrm{Zn}$ - and $\mathrm{Ni}-$ complexes. These results indicate that the 
frequencies calculated for compounds show good agreement with experimental values.

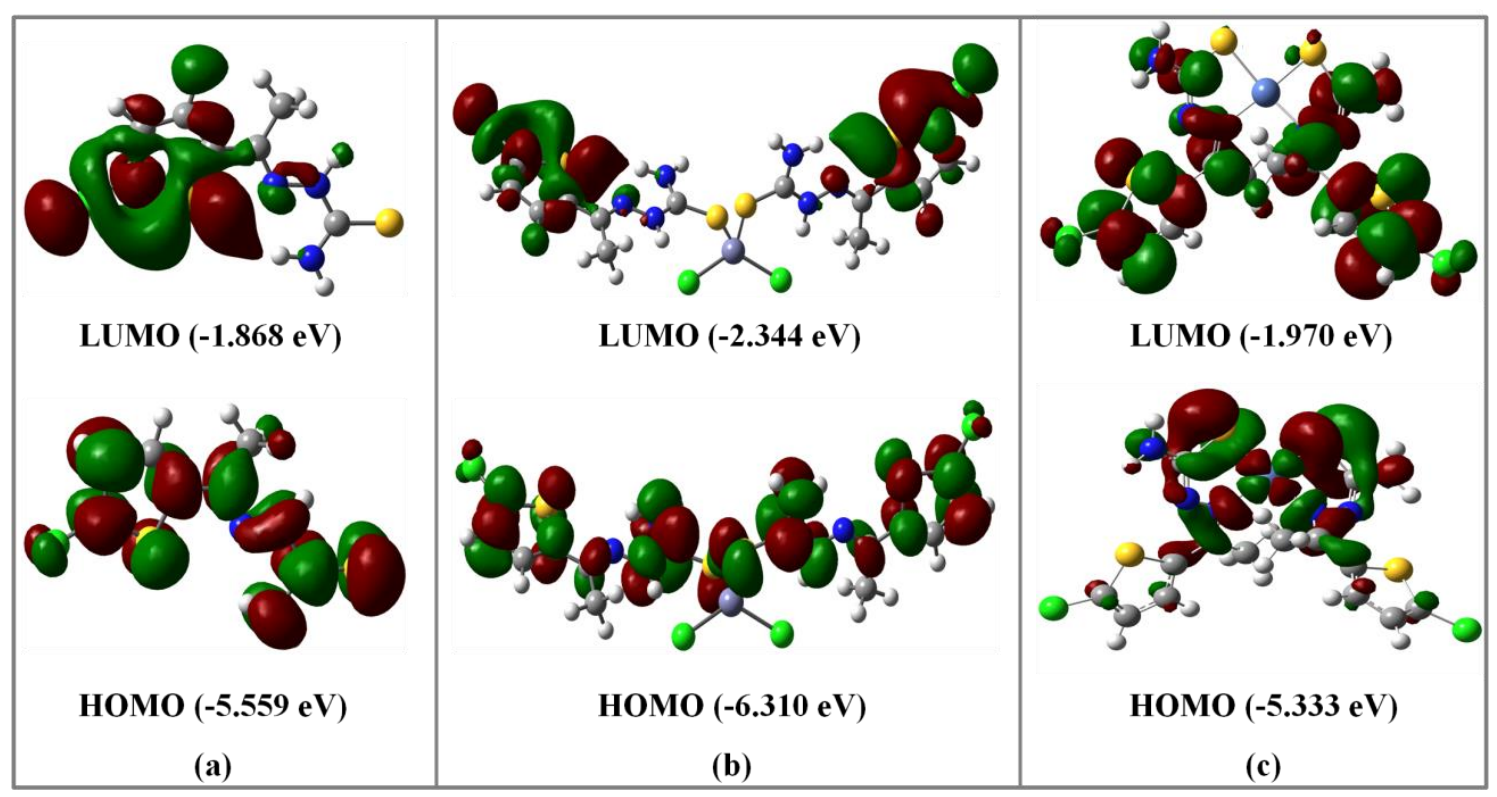

Figure 2. Molecular orbital surfaces and energy levels for the LUMO and HOMO of (a) Ligand, (b) Zncomplex and (c) Ni-complex.

Table 1. Selected optimized geometrical parameters of Ligand, Zn- and Ni-complexes.

\begin{tabular}{|c|c|c|c|c|c|}
\hline Parameters & Ligand & Parameters & Zn-complex & Parameters & Ni-complex \\
\hline \multicolumn{6}{|c|}{ Bond lengths $(\AA)$} \\
\hline Cl1-C6 & 1.730 & $\mathrm{Cl1}-\mathrm{C} 6$ & 1.729 & $\mathrm{Cl1}-\mathrm{C} 6$ & 1.733 \\
\hline $\mathrm{S} 1-\mathrm{C} 1$ & 1.678 & $\mathrm{~S} 1-\mathrm{C} 1$ & 1.717 & $\mathrm{~S} 1-\mathrm{C} 1$ & 1.755 \\
\hline S2-C6 & 1.743 & S2-C6 & 1.742 & S2-C6 & 1.742 \\
\hline S2-C3 & 1.758 & S2-C3 & 1.758 & $\mathrm{~S} 2-\mathrm{C} 3$ & 1.764 \\
\hline $\mathrm{N} 1-\mathrm{C} 1$ & 1.344 & $\mathrm{~N} 1-\mathrm{C} 1$ & 1.338 & $\mathrm{~N} 1-\mathrm{C} 1$ & 1.355 \\
\hline $\mathrm{N} 2-\mathrm{N} 3$ & 1.355 & $\mathrm{~N} 2-\mathrm{N} 3$ & 1.370 & $\mathrm{~N} 2-\mathrm{N} 3$ & 1.381 \\
\hline $\mathrm{N} 2-\mathrm{C} 1$ & 1.376 & $\mathrm{~N} 2-\mathrm{C} 1$ & 1.352 & $\mathrm{~N} 2-\mathrm{C} 1$ & 1.314 \\
\hline $\mathrm{N} 3-\mathrm{C} 2$ & 1.298 & $\mathrm{~N} 3-\mathrm{C} 2$ & 1.296 & $\mathrm{~N} 3-\mathrm{C} 2$ & 1.312 \\
\hline $\mathrm{C} 2-\mathrm{C} 3$ & 1.456 & C2-C3 & 1.458 & $\mathrm{C} 2-\mathrm{C} 3$ & 1.452 \\
\hline $\mathrm{C} 2-\mathrm{C} 7$ & 1.510 & $\mathrm{C} 2-\mathrm{C} 7$ & 1.506 & $\mathrm{C} 2-\mathrm{C} 7$ & 1.508 \\
\hline C3-C4 & 1.378 & C3-C4 & 1.378 & C3-C4 & 1.387 \\
\hline C4-C5 & 1.423 & C4-C5 & 1.422 & C4-C5 & 1.415 \\
\hline \multirow[t]{3}{*}{ C5-C6 } & 1.367 & C5-C6 & 1.368 & C5-C6 & 1.370 \\
\hline & & $\mathrm{Zn} 1-\mathrm{S} 1$ & 2.434 & $\mathrm{Ni}-\mathrm{S} 1$ & 2.199 \\
\hline & & $\mathrm{Zn} 1-\mathrm{Cl} 2$ & 2.261 & $\mathrm{Ni}-\mathrm{N} 3$ & 1.905 \\
\hline RMSE* & 0.023 & & 0.027 & & 0.024 \\
\hline \multicolumn{6}{|c|}{ Bond angles $\left({ }^{\circ}\right)$} \\
\hline C6-S2-C3 & 90.71 & C6-S2-C3 & 90.70 & C6-S2-C3 & 90.46 \\
\hline $\mathrm{C} 1-\mathrm{N} 2-\mathrm{N} 3$ & 121.36 & $\mathrm{C} 1-\mathrm{N} 2-\mathrm{N} 3$ & 117.86 & $\mathrm{C} 1-\mathrm{N} 2-\mathrm{N} 3$ & 112.30 \\
\hline $\mathrm{C} 2-\mathrm{N} 3-\mathrm{N} 2$ & 119.06 & $\mathrm{C} 2-\mathrm{N} 3-\mathrm{N} 2$ & 119.55 & $\mathrm{C} 2-\mathrm{N} 3-\mathrm{N} 2$ & 115.36 \\
\hline $\mathrm{N} 1-\mathrm{C} 1-\mathrm{S} 1$ & 125.11 & $\mathrm{~N} 1-\mathrm{C} 1-\mathrm{S} 1$ & 119.48 & $\mathrm{~N} 1-\mathrm{C} 1-\mathrm{S} 1$ & 118.33 \\
\hline $\mathrm{N} 1-\mathrm{C} 1-\mathrm{N} 2$ & 115.13 & $\mathrm{~N} 1-\mathrm{C} 1-\mathrm{N} 2$ & 117.00 & $\mathrm{~N} 1-\mathrm{C} 1-\mathrm{N} 2$ & 118.21 \\
\hline $\mathrm{N} 2-\mathrm{C} 1-\mathrm{S} 1$ & 119.76 & N2-C1-S1 & 123.50 & $\mathrm{~N} 2-\mathrm{C} 1-\mathrm{S} 1$ & 123.38 \\
\hline $\mathrm{N} 3-\mathrm{C} 2-\mathrm{C} 3$ & 116.54 & $\mathrm{~N} 3-\mathrm{C} 2-\mathrm{C} 3$ & 115.48 & $\mathrm{~N} 3-\mathrm{C} 2-\mathrm{C} 3$ & 124.26 \\
\hline
\end{tabular}


Betül ŞEN YÜKSEL

\begin{tabular}{|c|c|c|c|c|c|}
\hline $\mathrm{N} 3-\mathrm{C} 2-\mathrm{C} 7$ & 123.23 & $\mathrm{~N} 3-\mathrm{C} 2-\mathrm{C} 7$ & 124.57 & $\mathrm{~N} 3-\mathrm{C} 2-\mathrm{C} 7$ & 118.74 \\
\hline $\mathrm{C} 3-\mathrm{C} 2-\mathrm{C} 7$ & 120.23 & C3-C2-C7 & 119.95 & $\mathrm{C} 3-\mathrm{C} 2-\mathrm{C} 7$ & 116.97 \\
\hline $\mathrm{C} 2-\mathrm{C} 3-\mathrm{S} 2$ & 119.92 & $\mathrm{C} 2-\mathrm{C} 3-\mathrm{S} 2$ & 120.06 & $\mathrm{C} 2-\mathrm{C} 3-\mathrm{S} 2$ & 125.28 \\
\hline C4-C3-S2 & 110.60 & $\mathrm{C} 4-\mathrm{C} 3-\mathrm{S} 2$ & 110.61 & $\mathrm{C} 4-\mathrm{C} 3-\mathrm{S} 2$ & 110.16 \\
\hline $\mathrm{C} 4-\mathrm{C} 3-\mathrm{C} 2$ & 129.48 & $\mathrm{C} 4-\mathrm{C} 3-\mathrm{C} 2$ & 129.34 & $\mathrm{C} 4-\mathrm{C} 3-\mathrm{C} 2$ & 124.55 \\
\hline $\mathrm{C} 3-\mathrm{C} 4-\mathrm{C} 5$ & 114.03 & C3-C4-C5 & 114.04 & C3-C4-C5 & 114.61 \\
\hline C6-C5-C4 & 111.76 & C6-C5-C4 & 111.74 & C6-C5-C4 & 111.23 \\
\hline S2-C6-Cl1 & 120.36 & S2-C6-Cl1 & 120.41 & S2-C6-C11 & 120.32 \\
\hline C5-C6-Cl1 & 126.75 & C5-C6-C11 & 126.67 & C5-C6-Cl1 & 126.15 \\
\hline \multirow[t]{7}{*}{ C5-C6-S2 } & 112.89 & C5-C6-S2 & 112.92 & C5-C6-S2 & 113.53 \\
\hline & & $\mathrm{S} 1-\mathrm{Zn} 1-\mathrm{S} 1^{\mathrm{i}}$ & 113.21 & S3-Ni1-S1 & 95.19 \\
\hline & & $\mathrm{S} 1-\mathrm{Zn} 1-\mathrm{Cl} 2$ & 108.41 & N3-Ni1-S1 & 86.11 \\
\hline & & $\mathrm{S} 1-\mathrm{Zn} 1-\mathrm{Cl} 2^{\mathrm{i}}$ & 103.0 & N3-Ni1-S3 & 160.52 \\
\hline & & $\mathrm{Cl} 2-\mathrm{Zn} 1-\mathrm{Cl} 2^{\mathrm{i}}$ & 120.60 & N3-Ni1-N6 & 99.02 \\
\hline & & & & N6-Ni1-S1 & 160.72 \\
\hline & & & & N6-Ni1-S3 & 86.14 \\
\hline RMSE* & 1.30 & & 2.32 & & 1.37 \\
\hline
\end{tabular}

*Experimental values for the calculation of RMSE are used from Ref. [18] for ligand and from Ref. [15] for Zn- and Ni-complexes. Symmetry code: (i) $1-x,+y, 3 / 2-z$

\section{$\mathrm{N}-\mathrm{H}$ vibrations}

The high frequency area in the left part of the FTIR spectrum above $3000 \mathrm{~cm}-1$ appears as a characteristic region representing $\mathrm{N}-\mathrm{H}$ stretching vibrations [29]. The values of the $\mathrm{NH} 2$ symmetric stretching vibrations obtained from B3LYP method are found at $3244.4 \mathrm{~cm}-1$ (ligand), $3274.0 \mathrm{~cm}-1$ (Zn-complex) and $3358.8 \mathrm{~cm}-1$ (Ni-complex) while these frequencies are observed in the experimental spectrum at 3223, 3296 and $3384 \mathrm{~cm}$ 1,respectively. The bands at 3151 and $3157 \mathrm{~cm}-1$ belong to hydrazine $v \mathrm{NH}$ vibration in the experimental spectra of the ligand and $\mathrm{Zn}$-complex, respectively, whereas vibrations obtained from B3LYP method corresponding to those are found at 3167.3 and $3131.0 \mathrm{~cm}-1$. This band is absent from IR and theoretical spectrum of Ni-complex indicating that the ligand in complex emerges as the thiol tautomer in the solid-state when passing from the ligand to complex.

\section{$\mathrm{C}=\mathrm{N}$ vibrations}

The observed shift towards higher or lower frequency in $\mathrm{C}=\mathrm{N}$ bands during complexation indicates the evidence of coordination of metal atom with an azomethine nitrogen atom. After the complexation, the $\mathrm{C}=\mathrm{N}$ bond stretching vibrations of Ni-complex are experimentally observed at 1547 cm-1 which exhibits a shift to a lower frequency region in comparison with the free ligand counterparts [ $1575 \mathrm{~cm}-1]$ by about $28 \mathrm{~cm}-1$. This observation points out that, as also reported in the previous X-ray studies, thiosemicarbazones are coordinated to the metal center as a bidentate ligand through azomethine nitrogen and thiocarbonyl sulphur atoms. The $\mathrm{C}=\mathrm{N}$ vibrations of $\mathrm{Zn}$-complex that appeared at $1573 \mathrm{~cm}-1$ are almost the same in comparison with those observed for the ligand. These stretching bands are calculated at 1581.1, 1594.2 and $1546.0 \mathrm{~cm}-1$ for ligand, $\mathrm{Zn}$-complex and Ni-complex, respectively.

\section{$\mathrm{N}-\mathrm{N}$ vibrations}

The N-N bond stretching vibration at $1065 \mathrm{~cm}-1$ in the experimental spectrum of the ligand is observed in the Zn-complex at $995 \mathrm{~cm}-1$ while these vibrations are recorded at $944 \mathrm{~cm}-1$ in the spectrum of Ni-complex which is a lower frequency region. Calculated values are found to be 1073.9, 1017.7 and $975.5 \mathrm{~cm}-1$ for ligand, $\mathrm{Zn}$-complex and Nicomplex, respectively.

Ring vibrations

C-H stretching bands for the heteroaromatic structures such as furans, pyrroles and thiophenes usually take place in between 3100 and $3000 \mathrm{~cm}-1$ as weak bands because of the small dipole moments of these bonds [30,31]. The symmetric/asymmetric $\mathrm{C}-\mathrm{H}$ stretching frequencies of thiophene rings are calculated with B3LYP at 3100.8/3083.6 cm-1 for 
Betül ŞEN YÜKSEL

ligand, at 3112.3/3089.6 cm-1 for Zn-complex and 3120.0/3089.6 cm-1 for Ni-complex. The stretching vibrations of the thiophene ring are generally observed within 1500-1540, 1400-1445 and 1335-
$1365 \mathrm{~cm}-1$ wavenumber ranges [32,33]. For all complexes, detailed calculation results regarding the stretching vibrations for the thiophene ring are presented in Table 3.

Table 3. Comparison of the observed and calculated vibrational frequencies $\left(\mathrm{cm}^{-1}\right)$ for all complexes.

\begin{tabular}{|c|c|c|c|}
\hline \multicolumn{4}{|c|}{ B3LYP/6-31G $(\mathrm{d}, \mathrm{p})$} \\
\hline Modes & Ligand & Zn-complex & Ni-complex \\
\hline$v_{a s} \mathrm{NH}_{2}$ & 3298.0 & 3321.6 & 3398.9 \\
\hline$v_{s} \mathrm{NH}_{2}$ & 3244.4 & 3274.0 & 3358.8 \\
\hline$v \mathrm{NH}$ & 3186.6 & 3131.0 & - \\
\hline$v_{s} \mathrm{CH}_{\text {ring }}$ & 3100.8 & 3112.3 & 3120.0 \\
\hline$v_{a s} \mathrm{CH}_{\text {ring }}$ & 3083.6 & 3089.6 & 3107.1 \\
\hline$v_{a s} \mathrm{CH}_{3}$ & 3005.5 & 3049.6 & 3001.8 \\
\hline$v_{s} \mathrm{CH}_{3}$ & 2919.7 & 2945.0 & 2936.9 \\
\hline$\nu \mathrm{C}=\mathrm{N}$ & 1581.1 & 1594.2 & 1546.0 \\
\hline$\alpha \mathrm{NH}_{2}$ & 1562.1 & 1566.3 & 1577.6 \\
\hline$v_{a s} \mathrm{C}=\mathrm{C}_{\text {ring }}$ & 1533.9 & 1519.9 & 1509.3 \\
\hline$\nu \mathrm{C}=\mathrm{N}$ & - & - & 1495.6 \\
\hline$\gamma \mathrm{N} 2 \mathrm{H}$ & 1505.3 & 1538.3 & - \\
\hline$v_{s} \mathrm{C}=\mathrm{C}_{\text {ring }}$ & 1431.2 & 1443.6 & 1413.2 \\
\hline$u m \mathrm{CH}_{3}$ & 1366.3 & 1365.5 & 1326.4 \\
\hline$v \mathrm{CC}_{\text {ring }}$ & 1313.6 & 1314.2 & 1304.3 \\
\hline$\beta_{s} \mathrm{CH}_{\text {ring }}$ & 1197.8 & 1198.3 & 1201.9 \\
\hline$\beta_{a s} \mathrm{CH}_{\text {ring }}$ & 1060.9 & 1044.2 & 1075.7 \\
\hline$v \mathrm{NN}$ & 1073.9 & 1017.7 & 975.5 \\
\hline$\Gamma_{\text {as }} \mathrm{CH}_{\text {ring }}$ & 851.4 & 858.7 & 864.7 \\
\hline$v \mathrm{C}=\mathrm{S}$ & 823.3 & 803.8 & - \\
\hline$\Gamma_{s} \mathrm{CH}_{\text {ring }}$ & 768.9 & 774.5 & 775.4 \\
\hline$v \mathrm{ZnS}$ & & 522.2 & \\
\hline$v_{s} \mathrm{NiS}$ & & & 524.0 \\
\hline$v_{s} \mathrm{NiN}$ & & & 429.6 \\
\hline RMSE & 14.74 & 20.09 & 19.40 \\
\hline
\end{tabular}

3.4. Hirshfeld Surface analysis for ligand, $\mathrm{Zn}$ and Ni-complexes

The three-dimensional HSs are generated for the aforementioned structures, and are represented in Figures 3a-c showing surfaces that have been mapped with dnorm (-0.100 to 2.500), shape index (-1.000 to 1.000) and curvedness. As shown in Figure $3 \mathrm{a}$, the Hirshfeld surface for ligand exhibits two bright-red spots near the terminal $\mathrm{N}-\mathrm{H}$ and $\mathrm{S}$ atoms corresponding to donor and acceptor atoms, respectively, which are evidence of the presence of intermolecular $\mathrm{N}-\mathrm{H} \cdots \mathrm{S}$ interactions. The pairwise $\mathrm{Cl} \cdots \mathrm{S}$ interactions are mapped by faint-red spots that appear on the right and left of the surface. Shape index and curvedness can be used to indicate the presence of stacking arrangements, such as $\mathrm{C}-$ $\mathrm{H} \cdots \pi$ and $\pi \cdots \pi$ interactions. The shape-index surface indicates a blue convexity representing the donor atom and a red concavity representing the acceptor atom. The large flat region delineated by a blue outline on the curvedness maps refers to the stacking interactions between neighboring molecules. The existence of $\pi \cdots \pi$ interactions in the crystal structure of ligand is indicated through the appearance of a flat region around both sides of the thiophene ring in the curvedness plots (Figure 3c), 
Betül ŞEN YÜKSEL

as well as by red and blue triangles on the thiophene rings in shape-index surface (Figure 3b). Both $\mathrm{Cl}$ atoms act as an acceptor to two hydrogen atoms belonging to each of $\mathrm{NH} 2$ moieties, separately, and correspond to $\mathrm{N}-\mathrm{H} \cdots \mathrm{Cl}$ bonds which appear as two pairs of darkest-red spots near the $\mathrm{Cl}$-atoms on the Hirshfeld surfaces of Zn-complex. While two of them are shown in Figure 3a, the others are located on the reverse side of the surface. It should be noted that two bright red spots near the $\mathrm{NH} 2$ group are also related to the interaction of $\mathrm{N}-\mathrm{H} \cdots \mathrm{Cl} . \mathrm{S} \cdots \mathrm{Cl} /$ $\mathrm{Cl} \cdots \mathrm{S}$ contacts are due to the presence of $\mathrm{S} \cdots \mathrm{Cl}$ interatomic distances which are shorter than the sum of their van der Waals radii (rvdW: $3.55 \AA$ [34]), and are represented by small, pale-red spots near atoms $\mathrm{S}$ and $\mathrm{Cl}$ in Figure $3 \mathrm{a}$. In the views of the Hirshfeld surfaces for the Ni-complex in Figure 3a, the bright-red spots near $\mathrm{S}$ (thiolate) and the $\mathrm{N}$ (imino) atoms reflect intermolecular $\mathrm{N}-\mathrm{H} \cdots \mathrm{S}$ and $\mathrm{N}-\mathrm{H} \cdots \mathrm{N}$ interactions which play a significant role in the formation of inversion dimmers. The presence of a short interatomic $\mathrm{H} \cdots \mathrm{H}, \mathrm{S} \cdots \mathrm{H}$ and $\mathrm{Cl} \cdots \mathrm{S}$ contacts are observable as diminutive, palered spots near the thiophene- $\mathrm{H}$ and thiophene- $\mathrm{H}$, thiophene-S and methyl-H, as well as thiophene-S and $\mathrm{Cl}$ atoms, respectively. The lack of the red and blue triangles on the shape index surface of $\mathrm{Zn}$ - and $\mathrm{Ni}$ - complexes indicates the absence of stacking interactions, i.e., $\mathrm{C}-\mathrm{H} \cdots \pi$ and $\pi \cdots \pi$ (Figure $3 \mathrm{~b}$ ). This result has been confirmed by the Hirshfeld surface mapped with curvedness (Figure 3c) and X-ray crystal structural analysis for both complexes $[15,18]$.
Ligand

(a)

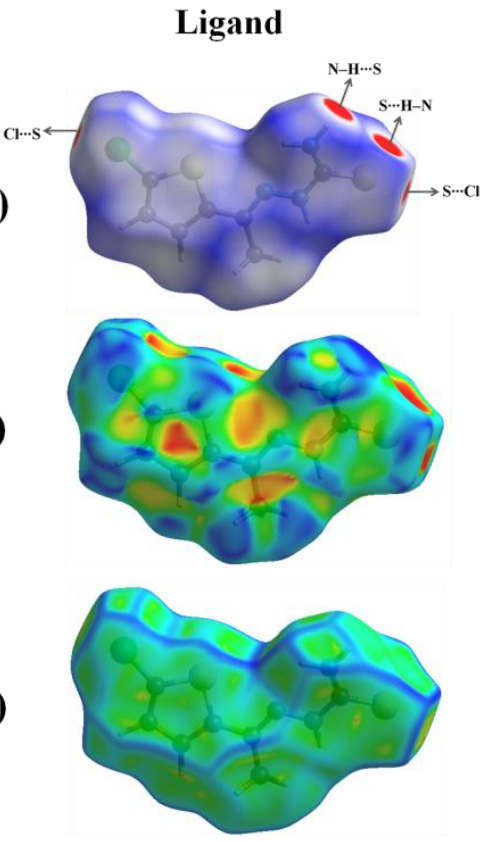

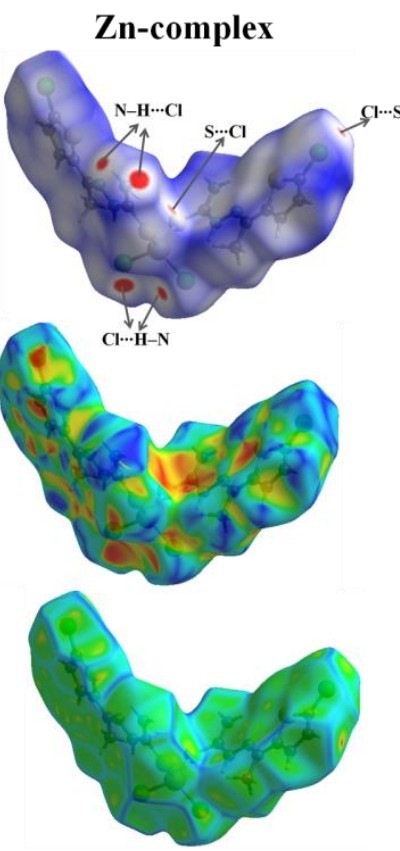

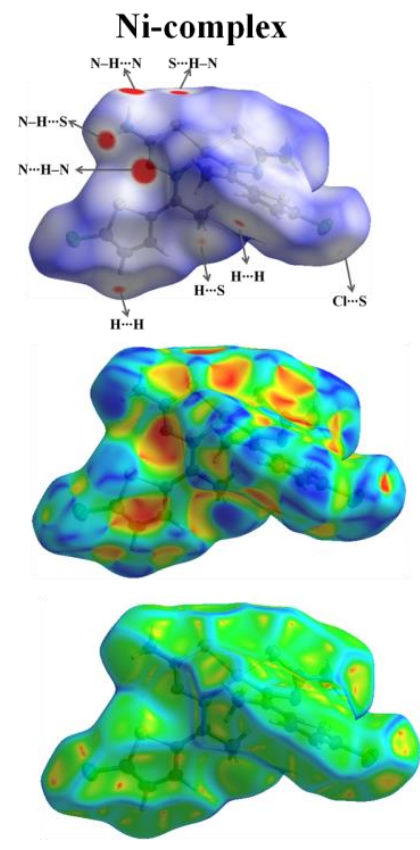

Figure 3. View of the Hirshfeld surfaces mapped with (a) d norm $\underline{d}_{\text {norm }}$ with the red spot showing the involvement of the hydrogen bonds and close contacts, (b) shape-index, (c) curvedness for ligand, $\mathrm{Zn}$ - and Ni-complexes.

\subsection{Two-dimensional fingerprint of all complexes}

The overall two-dimensional fingerprint plots of all compounds are shown in Figure $4 \mathrm{a}$ and those delineated into $\mathrm{S} \cdots \mathrm{H} / \mathrm{H} \cdots \mathrm{S}, \mathrm{H} \cdots \mathrm{H}, \mathrm{Cl} \cdots \mathrm{H} / \mathrm{H} \cdots \mathrm{Cl}$, $\mathrm{N} \cdots \mathrm{H} / \mathrm{H} \cdots \mathrm{N}, \quad \mathrm{C} \cdots \mathrm{C}, \quad \mathrm{C} \cdots \mathrm{H} / \mathrm{H} \cdots \mathrm{C}$, and intercontacts are illustrated in Figures $4 \mathrm{~b}-\mathrm{g}$. As expected, Hirshfeld surface analysis of ligand shows that the proportion of $\mathrm{S} \cdots \mathrm{H} / \mathrm{H} \cdots \mathrm{S}$ interactions have the greatest contribution $(27.1 \%)$ to the total Hirshfeld surface, arising from the intermolecular $\mathrm{N}-\mathrm{HN} \cdots \mathrm{S}$ hydrogen-bond linking the two independent molecules. $\mathrm{S} \cdots \mathrm{H} / \mathrm{H} \cdots \mathrm{S}$ interactions are viewed as two thin spikes of almost equal lengths at de+di 2.44 $\AA$ in Figure $4 b$. The next most significant contribution with $23.8 \%$ of the overall surface is due to $\mathrm{H} \cdots \mathrm{H}$ contacts, which indicates van der Waals interactions, and appear as 
widely scattered points in the fingerprint maps with the tip at de+di 2.6 $\AA$ (Figure 4c). The FP plots corresponding to $\mathrm{Cl} \cdots \mathrm{H} / \mathrm{H} \cdots \mathrm{Cl}$ contacts for ligand have the smallest contribution to the Hirshfeld surface, i.e. $16.4 \%$, compared to $\mathrm{Zn}$ - and $\mathrm{Ni}$ complexes, and are reflected in Figure $4 \mathrm{~d}$ as a symmetrical distribution of points with the edges at $\mathrm{de}+\mathrm{di} \sim 2.94 \AA$. C $\cdots \mathrm{C}$ contacts only cover about $4.8 \%$ of the Hirshfeld surface but are significant due to providing evidence of the $\pi \cdots \pi$ interactions which were reported in X-ray diffraction studies. As seen in Figure 4f, C $\cdots \mathrm{C}$ contacts appear as points with a rocket-shaped distribution at around $\mathrm{de}=\mathrm{di} \sim 1.8 \AA$. The absence of characteristic wings in the fingerprint plot as illustrated in Figure $4 \mathrm{~g}$, and the smaller percentage of $\mathrm{C} \cdots \mathrm{H} / \mathrm{C} \cdots \mathrm{H}(6.6 \%)$ interactions exhibit inadequate presence of $\mathrm{C}-\mathrm{H} \cdots \pi$ interactions in the crystal. This observation also supports X-ray study of the ligand.

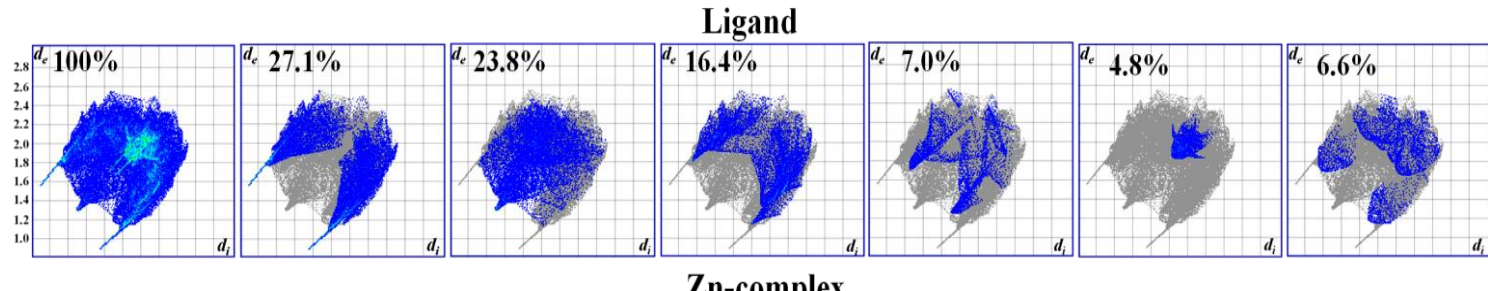

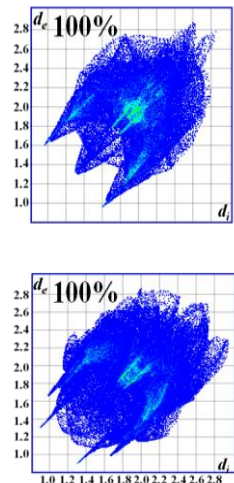

ALL
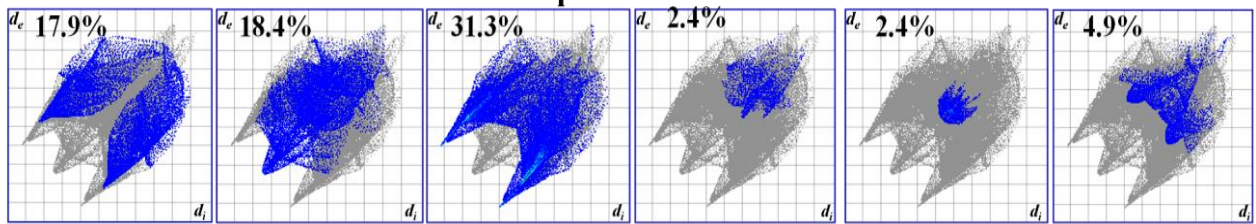

Ni-complex
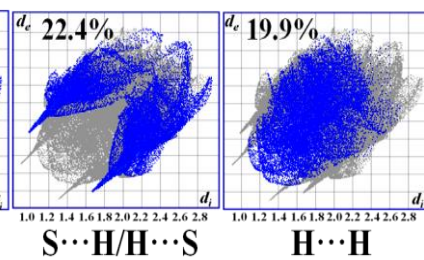

(b)

(c)

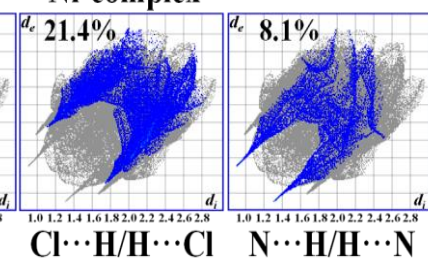

(d)

(e)

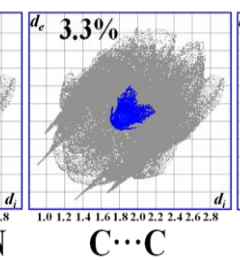

(f)

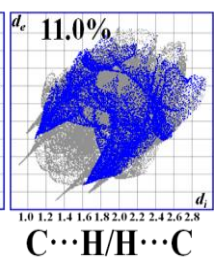

(g)

Figure 4. Decomposed fingerprint plots along with related HS areas and percentage contributions to the total HS for major intermolecular contacts (a) all (b) S $\bullet \bullet H / H \bullet \bullet S$, (c) $\mathrm{H} \bullet \bullet H$, (d) $\mathrm{Cl} \bullet \bullet \mathrm{H} / \mathrm{H} \bullet \bullet \mathrm{Cl}$, (e) $\mathrm{N} \bullet \bullet \mathrm{H} / \mathrm{H} \bullet \bullet \mathrm{N}$ (f) $\mathrm{C} \bullet \bullet \mathrm{C}$ and $(\mathrm{g}) \mathrm{C} \bullet \bullet \mathrm{H} / \mathrm{H} \bullet \bullet \mathrm{C}$ for the all complexes.

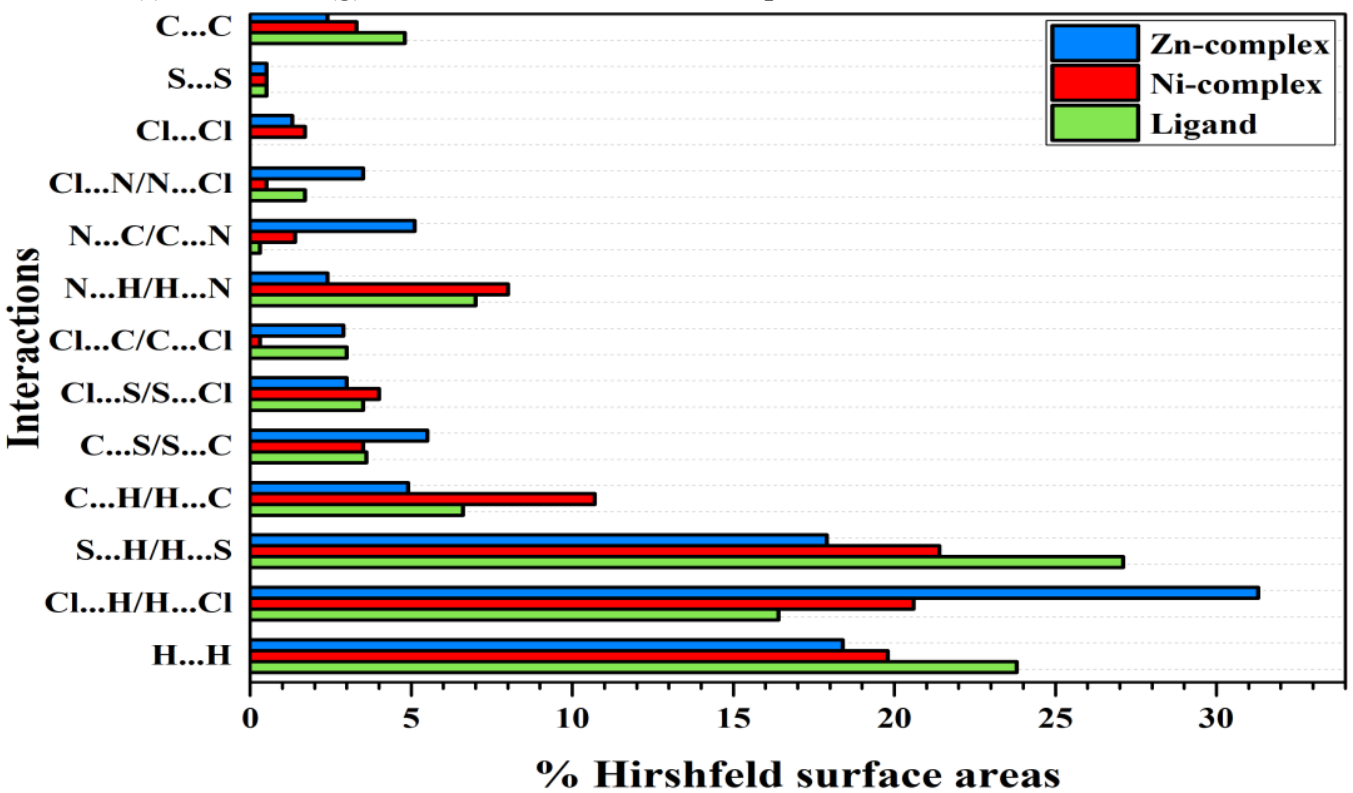


Betül ŞEN YÜKSEL

Figure 5. Relative contributions to the Hirshfeld surface area for the various intermolecular contacts in all complexes.

Hirshfeld surface analysis of $\mathrm{Zn}$-complex shows an increased amount of $\mathrm{Cl} \cdots \mathrm{H}$ and $\mathrm{H} \cdots \mathrm{Cl}$ interactions compared to the ligand and $\mathrm{Ni}$-complex due to the existence of the intermolecular $\mathrm{N}-\mathrm{H} \cdots \mathrm{Cl}$ interactions in the crystal packing. $\mathrm{Cl} \cdots \mathrm{H} / \mathrm{H} \cdots \mathrm{Cl}$ contacts which have $31.3 \%$ contribution to the total Hirshfeld surface manifest themselves as two distinct spikes with de+di 2.3 $\AA$ in the 2D fingerprint plots (Figure 4d). The non-directional $\mathrm{H} \cdots \mathrm{H}$ contacts represent the second important contribution, amounting to $18.4 \%$ with a single broad peak at $\mathrm{de}=\mathrm{di} \sim 1.3 \AA$ (Figure $4 \mathrm{c}$ ). The $\mathrm{S} \cdots \mathrm{H} / \mathrm{H} \cdots \mathrm{S}$ interactions, which are indicated by a symmetrical distribution of points with the edges at $\mathrm{de}+\mathrm{di} \sim 2.98 \AA$, have the lowest proportion for all of the compounds studied, making up only $17.9 \%$ of the overall Hirshfeld surface (Figure 4b). There is a minor contribution of $4.9 \%$ to the surface due to $\mathrm{C} \cdots \mathrm{H} / \mathrm{C} \cdots \mathrm{H}$ contacts originating from medium or longer contacts in the structure rather than the shorter ones or $\mathrm{C}-\mathrm{H} \cdots \pi$ interactions (Figure $4 \mathrm{~g}$ ).

The presence of intermolecular $\mathrm{N}-\mathrm{HN} \cdots \mathrm{S}$ and $\mathrm{N}-$ $\mathrm{HN} \cdots \mathrm{N}$ interactions in $\mathrm{Ni}$-complex is evident from the FP plots delineated into $\mathrm{S} \cdots \mathrm{H} / \mathrm{H} \cdots \mathrm{S}$ and $\mathrm{N} \cdots \mathrm{H} / \mathrm{H} \cdots \mathrm{N}$ contacts, and these interactions play a pivotal role in the supramolecular arrangement. The $\mathrm{S} \cdots \mathrm{H} / \mathrm{H} \cdots \mathrm{S}$ and $\mathrm{N} \cdots \mathrm{H} / \mathrm{H} \cdots \mathrm{N}$ contacts are found to contribute a total of 22.4 and $8.1 \%$ to the Hirshfeld surface, respectively, which are reflected in the two sharp and narrow spikes of almost equal lengths with their tips at de+di 2.65 $\AA$ and de+di $2.19 \AA$. The pairwise $\mathrm{S} \cdots \mathrm{H}$ and $\mathrm{N} \cdots \mathrm{H}$ contacts are demonstrated in Figures $4 \mathrm{~b}$ and $4 \mathrm{e}$, respectively. In contrast to $\mathrm{Zn}$-complex, the crystal structure of $\mathrm{Ni}$ complex does not exhibit $\mathrm{N}-\mathrm{H} \cdots \mathrm{Cl}$ interactions as pointed out in our earlier X-ray study [15] but the $\mathrm{Cl} \cdots \mathrm{H} / \mathrm{H} \cdots \mathrm{Cl}$ interaction comprises $21.4 \%$ of the total Hirshfeld surface due to close contacts. The pairwise $\mathrm{Cl} \cdots \mathrm{H}$ contacts are characterized by a pair of sharp and short symmetric spikes in the twodimensional fingerprint maps with a prominent long spike at de+di 2.82 $\AA$ (Figure $4 d$ ) which is approximately less than the sum of van der Waals radii (2.9 §) [34]. Another notable contact is $\mathrm{H} \cdots \mathrm{H}$ interaction which is represented by the largest area of the fingerprint plot with a high concentration in the middle region around de, di distances greater than their corresponding van der Waals separations and the proportion of these interactions cover $19.9 \%$ of the whole Hirshfeld surface (Figure 4c). Unlike the related interaction observed for ligand and $\mathrm{Zn}$-complex, there is a pair of characteristic wings (with a prominent spike at de+di 2.69 $\AA$ ) in the two-dimensional fingerprint maps delineated into $\mathrm{C} \cdots \mathrm{H} / \mathrm{C} \cdots \mathrm{H}$ contacts. Furthermore, the $\mathrm{C} \cdots \mathrm{H} / \mathrm{C} \cdots \mathrm{H}$ interactions make up to $11.0 \%$ of the total HS being greater than those observed in ligand and Zn-complex (Figure 4g). These results suggest the influence of the interatomic short $\mathrm{C} \cdots \mathrm{H}$ contacts instead of intermolecular $\mathrm{C}-\mathrm{H} \cdots \pi$ interactions.

Apart from these above, the presence of the small contributions from other remaining interatomic contacts that have a negligible effect on the crystal packing is observed for all compounds. Figure 5 depicts the percentages of contributions to the overall Hirshfeld surface for all contacts in the related compounds.

\section{Conclusion}

In the present study, by the use of quantum chemical calculations we thoroughly have investigated the molecular geometry, vibrational spectra, HOMO and LUMO energies for thiosemicarbazone ligand and its $\mathrm{Zn}$ - and $\mathrm{Ni}$ complexes. The geometrical structure parameters for the three compounds are in good agreement with available related experimental crystal data. In comparison to bond angles, our results indicate that there exists a negligible deviation for bond lengths. The FT-IR vibrational frequencies of all compounds are calculated and the vibrational assignments corresponding to wavenumbers have been determined and compared with their experimental spectrum.

The study of X-ray diffraction and analysis of FTIR spectra shows unambiguously that the thiosemicarbazone ligand coordinated to Zinc ion remains as a thione tautomer while the ligand coordinated to $\mathrm{Ni}$ atom appears as a thiol form. Through the molecular orbital analysis, we found that the energy gap between HOMO and LUMO is 
Betül ŞEN YÜKSEL

largest for $\mathrm{Zn}$-complex which indicates that $\mathrm{Zn}$ complex is more stable and less reactive than ligand and Ni-complex. Also, analyses of intermolecular interactions and close contacts in the crystal structures of all compounds have been performed by visualizing Hirshfeld surface and 2D fingerprint plots.

\section{Acknowledgments}

The author thanks Muhittin Aygün from Dokuz Eylül University, Department of Physics for the use of the Gaussian 09W/G View package programs. Dokuz Eylül University for the use of the Oxford Rigaku Xcalibur Eos Diffractometer (purchased under University Research Grant No: 2010.KB.FEN.13) is also greatly acknowledged.

\section{References}

[1] R.K. Singh, A.K. Singh, Synthesis, molecular structure, spectral analysis, natural bond order and intramolecular interactions of 2acetylpyridine thiosemicarbazone: a combined DFT and AIM approach. J. Mol.Struct.1094 (2015) 61-72.

[2] K. Alomar, M.A. Khan, M. Allain, G. Bouet, Synthesis, crystal structure, and characterization of 3-thiophene aldehyde thiosemicarbazone and its complexes with cobalt(II), nickel(II) and copper(II). Polyhedron 28 (2009) 1273-1280.

[3] T.S. Lobana, P. Kumari, M. Zeller, R.J. Butcher, The influence of the substituents at N1 nitrogen on geometry of nickel(II) complexes with heterocyclic thiosemicarbazones. Inorg. Chem. Commun. 11 (2008) 972-974.

[4] E. Pahonțu, C. Paraschivescu, D.-C. Ilieş, D. Poirier, C. Oprean, V. Păunescu, A. Gulea, T. Roșu, O. Bratu, Synthesis and Characterization of Novel Cu(II), Pd(II) and Pt(II) Complexes with 8Ethyl-2-hydroxytricyclo(7.3.1.02,7)tridecan-13 onethiosemicarbazone: Antimicrobial and in Vitro Antiproliferative Activity. Molecules 21 (2016) 674-692.

[5] M.-X. Li, D. Zhang, L.-Z. Zhang, J.-Y. Niu, Synthesis, crystal structures, and biological activities of 2-thiophene N(4)methylthiosemicarbazone and its unusual hexanuclear silver(I) cluster. Inorg. Chem. Commun. 13 (2010) 1268-1271.
[6] K. Alomar, A. Landreau, M. Kempf, M.A. Khan, M. Allain, G. Bouet, Synthesis, crystal structure, characterization of zinc(II), cadmium(II) complexes with 3-thiophene aldehyde thiosemicarbazone (3TTSCH). Biological activities of 3TTSCH and its complexes. J. Inorg. Biochem. 104 (2010) 397-404.

[7] R.A. Finch, M.C. Liu, S.P. Grill, W.C. Rose, R. Loomis, K.M. Vasquez, Y.C. Cheng, A.C. Sartorelli, Triapine (3-Aminopyridine-2carboxaldehyde thiosemicarbazone): A Potent Inhibitor of Ribonucleotide Reductase Activity with Broad Spectrum Antitumor Activity. Biochem. Pharmacol. 59 (2000) 983-991.

[8] Z. Tavsan, P.K. Yaman, E. Subasi, H.A. Kayali, Screening organometallic thiophene containing thiosemicarbazone ruthenium (II/III) complexes as potential anti tumour agents. J. Biol. Inorg. Chem. 23 (2018) 425-435.

[9] M. Khandani, T. Sedaghat, N. Erfani, M.R. Haghshenas, H.R. Khavasi, Synthesis, spectroscopic characterization, structural studies and antibacterial and antitumor activities of diorganotin complexes with 3methoxysalicylaldehyde thiosemicarbazone. J. Mol. Struct. 1037 (2013) 136-143.

[10] N. Öztürk, P. Kose Yaman, M. Yavuz, Ö. Öter, S. Timur, E. Subaşı, Synthesis, structural characterization, oxygen sensitivity, and antimicrobial activity of ruthenium(II) carbonyl complexes with thiosemicarbazones. J. Coordin. Chem. 67 (2014) 2688-2700.

[11] R. Pingaew, S. Prachayasittikul, S. Ruchirawat, Synthesis, Cytotoxic and Antimalarial Activities of Benzoyl Thiosemicarbazone Analogs of Isoquinoline and Related Compounds. Molecules 15 (2010) 988-996.

[12] P. Chellan, S. Nasser, L. Vivas, K.G.S. Smith, Cyclopalladated complexes containing tridentate thiosemicarbazone ligands of biological significance: Synthesis, structure and antimalarial activity. J. Organomet. Chem. 695 (2010) 22252232.

[13] S. Sharma, F. Athar, M. R. Maurya, A. Azam, Copper(II) complexes with substituted thiosemicarbazones of thiophene-2carboxaldehyde: synthesis, characterization and 
Betül ŞEN YÜKSEL

antiamoebic activity against E. Histolytica. Eur. J. Med. Chem. 40 (2005) 1414-1419.

[14] N. Gokhale, S. Jain, M. Yadav, Design and Virtual Screening Towards Synthesis of Novel Substituted Thiosemicarbozones as Ribonuleotide Reductase (RNR) Inhibitors with Improved Cellular Trafficking and Anticancer Activity. Curr. Top. Med. Chem. 15 (2015) 37-42.

[15] B. Şen, H. K. Kalhan, V. Demir, E.E. Güler, H. Ayar Kayali, E. Subaş1, Crystal structures, spectroscopic properties of new cobalt(II), nickel(II), zinc (II) and palladium(II) complexes derived from 2-acetyl-5-chloro thiophene thiosemicarbazone: Anticancer evaluation Mater. Sci. Eng. C 98 (2019) 550-559.

[16] D.K. Demertzi, A. Domopoulou, M.A. Demertzis, G. Valle, A. Papageorgiou, Palladium(II) complexes of 2-acetylpyridine N(4)methyl, N(4)-ethyl and N(4)-phenylthiosemicarbazones. Crystal structure of chloro(2acetylpyridine N(4)-methylthiosemicarbazonato) palladium(II). Synthesis, spectral studies, in vitro and in vivo antitumour activity. J. Inorg. Biochem. 68 (1997) 147-155.

[17] Y. Tian, C. Duan, C. Zhao, X. You, T.C.W. Mak, Z.Y. Zhang, Synthesis, Crystal Structure, and Second-Order Optical Nonlinearity of Bis(2-chlorobenzaldehyde thiosemicarbazone)cadmium Halides (CdL2X2; X ) Br, I). Inorg. Chem. 36 (1997) 1247-1252.

[18] P. Kose Yaman, B. Şen, C.S. Karagoz, E. Subaş1, Half-sandwich ruthenium-arene complexes with thiophen containing thiosemicarbazones: Synthesis and structural characterization. J. Organomet. Chem. 832 (2017) 27-35.

[19] A.D. Becke, Density-functional thermochemistry. III. The role of exact exchange. J. Chem. Phys. 98 (1993) 5648.

[20] C. Lee, W. Yang, R.G. Parr, Development of the Colle-Salvetti correlation-energy formula into a functional of the electron density. Phys. Rev. B Condens. Matter 37 (1988) 785.

[21] A.D. McLean, G.S. Chandler, Contracted Gaussian basis sets for molecular calculations. I. Second row atoms, Z=11-18. J. Chem. Phys. 72 (1980) 5639.
[22] M.J. Frisch, G.W. Trucks, H.B. Schlegel, G.E. Scuseria, M.A. Robb, J.R. Cheeseman, G. Scalmani, V. Barone, B. Mennucci, G.A. Petersson, H. Nakatsuji, M. Caricato, X. Li, H.P. Hratchian, A.F. Izmaylov, J. Bloino, G. Zheng, J.L. Sonnenberg, M. Hada, M. Ehara, K. Toyota, R. Fukuda, J. Hasegawa, M. Ishida, T. Nakajima, Y. Honda, O. Kitao, H. Nakai, T. Vreven, J.A. Montgomery Jr., J.E. Peralta, F. Ogliaro, M. Bearpark, J.J. Heyd, E. Brothers, K.N. Kudin, V.N. Staroverov, T. Keith, R. Kobayashi, J. Normand, K. Raghavachari, A. Rendell, J.C. Burant, S.S. Iyengar, J. Tomasi, M. Cossi, N. Rega, J.M. Millam, M. Klene, J.E. Knox, J.B. Cross, V. Bakken, C. Adamo, J. Jaramillo, R. Gomperts, R.E. Stratmann, O. Yazyev, A.J. Austin, R. Cammi, C. Pomelli, J.W. Ochterski, R.L. Martin, K. Morokuma, V.G. Zakrzewski, G.A. Voth, P. Salvador, J.J. Dannenberg, S. Dapprich, A.D. Daniels, O. Farkas, J.B. Foresman, J.V. Ortiz, J. Cioslowski, D.J. Fox, Gaussian 09, Revision D.01, Gaussian Inc., Wallingford, CT, 2013.

[23] A. Frisch, H.P. Hratchian, R.D. Dennington, II, T.A. Keith, John Millam, B. Nielsen, A.J. Holder, J. Hiscocks, GaussView Version 5.0.8, Gaussian Inc, Wallingford, CT, USA, 2009.

[24] F.L. Hirshfeld, Bonded-atom fragments for describing molecular charge densities. Theor. Chim. Acta 44 (1977) 129-138.

[25] S.K. Wolff, D.J. Grimwood, J.J. McKinnon, M.J. Turner, D. Jayatilaka, M.A. Spackman, CrystalExplorer 3.1 (2013), University of Western Australia, Crawley, Western Australia, 2005-2013, http://hirshfeldsurface.net/CrystalExplorer.

[26] M.A. Palafox, DFT computations on vibrational spectra: Scaling procedures to improve the wavenumbers. Phys. Sci. Rev. 3 (2018) 1-30.

[27] M. Szafran, A. Katrusiak, J. Koput, Z. Dega-Szafran, X-ray, MP2 and DFT studies of the structure, vibrational and NMR spectra of homarine. J. Mol. Struct.846 (2007) 1-12.

[28] J.A. Pople, H.B. Schlegel, R. Krishnan, D.J. Defrees, J.S. Binkley, M.J. Frisch, R.A. Whiteside, R.F. Hout. W.J. Hehre, Molecular orbital studies of vibrational frequencies. Int. J. Quantum Chem. 15 (1981) 269-278. 
[29] M. Silverstein, G.C. Basseler, C. Morill, Spectrometric Identification of Organic Compounds, Wiley, New York, 1981.

[30] C.N.R. Rao, Chemical Application of Infrared Spectroscopy, Academic Press, New york, 1981.

[31] N. Sundaraganesan, H. Saleem, S. Mohan, Spectrochimica Acta Part A, Vibrational spectra, assignments and normal coordinate analysis of 3aminobenzyl alcohol. 59 (2003) 2511- 2517.

[32] S.Ya. Khorshev, N.S. Vyazankin, A.N. Egorochkin, E.A. Chernyshev, V.I. Savushkina, O.V. Kuz'min, V.Z. Anisimova, Spectroscopic study of organosilicon derivatives of thiophene. Chemistry of Heterocyclic Compounds, 10 (1974) 413-417.

[33] Socrates, Infrared and Raman Characteristic Group Frequencies, Tables and Charts, Wiley, New York, 1974.

[34] A. Bondi, van der Waals Volumes and Radii. J.Phys.Chem. 68 (1964) 441-451. 